\title{
Temporal variations in the air, soil, and fiddler crab (Austruca perplexa) burrow temperatures in southern Thailand
}

\author{
Uthai Kuhapong ${ }^{a *}$ | Fahmida Wazed Tina ${ }^{a}$ (i) | Kiadtisak Limsakun ${ }^{a}$ | Suranan Watthanaphong ${ }^{a}$ | \\ Ekapote Luckban ${ }^{\text {a }}$ Teethat Piyakun
}

${ }^{a}$ Creative Innovation in Science and Technology Program, Faculty of Science and Technology, Nakhon Si Thammarat Rajabhat University, Nakhon Si Thammarat 80280 , Thailand.

Corresponding author: uthai_kuh@nstru.ac.th

\begin{abstract}
Fiddler crabs live in an intertidal habitat and face several environmental constraints. Extreme environmental conditions, especially temperature affects their growth and reproduction. They use several strategies to deal with extreme temperatures. Among these, constructing burrows is important. Burrows act as a refuge during very high or low temperatures. This study investigates the temporal variations in air temperature, burrow temperature of large-sized male and female Austruca perplexa crabs, and the soil temperature near their burrows in Nakhon Si Thammarat province, southern Thailand (tropical climate). Air, burrow and soil temperatures were measured every 30 min in a day using temperature sensors. We observed that from 8:00 up to and including 17:30, burrow temperature was lower than soil temperature, but other times, burrow temperature was higher than soil temperature. In the case of air temperature, it was lower than soil or burrow temperatures most of the time in a day. When we compared temperatures among air, soil, and burrows at day (6:00 up to 17:30) and night (18:00 up to 5:30), burrow temperature was lower than soil temperature during the day but was higher at night. The air temperature was lower than soil or burrow temperatures on both day and night. This study shows that $A$. perplexa crab burrows can modulate the inside temperature and maintain a suitable temperature for the crabs.
\end{abstract}

Keywords air temperature, crab burrow temperature, day and night, soil temperature, temperature sensor

\section{Introduction}

Fiddler crabs are intertidal organisms and they live on various habitats such as muddy sandy flats, salt marshes, and mangrove swamps (Crane 1975). They are among the most abundant organisms in their habitats and their densities may exceed $50 \mathrm{crabs} / \mathrm{m}^{2}$ (Bertness and Miller 1984; McCraith et al 2003; Tina et al 2015a, b). Both males and females construct burrows and stay inside the burrows during high tide (Tina et al $2015 \mathrm{a}, \mathrm{b}$ ). They are active on the surface and show various activities (e.g., feeding, fighting, waving, burrowing, grooming, etc.) during low tide (Tina et al 2016, 2019, Tina 2020; Tina and Muramatsu, 2020).

Their burrowing activity is very important for their habitats since it promotes soil aeration and thus oxidizes hydrogen sulphide. Hydrogen sulphide inhibits plant growth by affecting their nitrogen uptake and growth (Howarth and Teal 1979; Bradley and Morris 1990; Koch et al 1990; Wiessner et al 2005). Crab burrowing activity also reduces salinity by increasing water flow through the sediments. A higher salinity level negatively affects the growth and productivity of mangroves (McKee 1993; Sylla et al 1996; Twilley and Chen 1998). For these reasons, fiddler crabs are known as ecosystem engineers in their habitats (see Jones et al 1994; Kristensen 2008). Moreover, burrows have several advantages for the fiddler crabs. They provide shelters from predators and environmental extremes (e.g., very high or low temperature), they provide water for physiological needs, and they act as sites for moulting and breeding (Crane 1975; Christy 1982, 1987; Keeratipattarakarn et al 2020).

The intertidal animals live in a dry and open environment and face several environmental constraints (Chapman and Underwood 1996; Thurman 1998; Somero 2002; Schneider 2008; Miller et al 2009; Allen et al 2012). Among these environmental constraints, temperature is the most important since it affects their behaviour, physiology, growth, and reproduction (Weinstein 1998; Ruscoe et al 2004; Resgalla et al 2007; Allen et al 2012). In the case of fiddler crabs, very high or very low temperature affects their metabolic rates, heart rates, haemolymph osmolality, muscle hydration, ovarian development, and egg hatching success (Vernberg and Vernberg 1966; Eshky et al 1995; Matsumasa and Murai 2005; Colpo and López-Greco 2017; Principe et al 2018; Chou et al 2019). They have developed several physiological, morphological, and behavioural adaptations for dealing with the very high or low temperature (Eshky et al 1995; Thurman 1998; Yoder et al 2005; Levinton et al 2015; da Silva Vianna et al 2020). Moreover, their burrows act as a refuge through maintaining a suitable temperature when the outside temperature is very high or low (Powers and Cole, 1976; Wolfrath, 1992; Keeratipattarakarn et al 2020). Suitable burrow temperature is not only important for the 
physiology of fiddler crabs; it also influences their egg incubation rate (Christy and Salmon 1984; Eshky et al 1995; Reaney and Backwell 2007).

In this study, we would like to investigate the temporal variations of air, soil, and burrow temperatures of the fiddler crabs (Austruca perplexa) in southern Thailand (tropical climate), where the temperature is hot all the year round (average temperature $28-30{ }^{\circ} \mathrm{C}$ ). Previously, several studies have investigated the burrow temperatures of several fiddler crab species (Paraleptuca chlorophthalmus, Austruca annulipes, Gelasimus vocans, Leptuca panacea, Minuca virens, Afruca tangeri, Austruca mjoebergi, and Tubuca rosea) in East Africa, Portugal, Texas (U.S.A.), Australia and Thailand (Edney 1961; Powers and Cole 1976; Wolfrath 1992; Reaney and Backwell 2007; Keeratipattarakarn et al 2020). In the case of Thailand, only one study has been conducted on soil and burrow temperatures of $T$. rosea inside mangroves. However, no study has been conducted on the burrow temperature of the fiddler crab A. perplexa. Our hypotheses are (1) the temperatures of air, soil and fiddler crab burrows would be different at different times (i.e., hours) in a day, and (2) crab burrow temperature (male/female burrows) would be lower than soil temperature but higher than the air temperature at day but that would be higher than both air and soil temperatures at night.

\section{Materials and Methods}

\subsection{Study site}

The burrow temperature of the fiddler crabs (Austruca perplexa) was studied in Ban Nai Thung village, Thasala district, Nakhon Si Thammarat province. The population's size is approximately $300 \mathrm{~m}^{2}$ and no other fiddler crab species lives in this place. This $A$. perplexa population lives on a muddy-sandy flat. We conducted this study from September to October 2020.

\subsection{Biology of Austruca perlexa}

Both males and females of this species build burrows where males mostly build breeding burrows, and females build temporary refugee burrows. The lengths of male and female burrows are approximately $246 \mathrm{~mm}$ and $187 \mathrm{~mm}$, and depths are $192 \mathrm{~mm}$ and $140 \mathrm{~mm}$, respectively (Tina et al 2018). They are active on the surface during diurnal low tide. Males wave their major claws towards the wandering females to attract them towards the breeding burrows for mating (Tina et al 2018; Tina 2020; Tina and Muramatsu 2020). If a female selects a male, she approaches the male and enters the male burrow. Afterward, she stays with the male for 4-5 days until she ovulates the eggs. Then the male leaves the burrow and either build another burrow or takes over a burrow from another male through fighting. On the other hand, the female stays inside the male breeding burrow for another 14-15 days for egg incubation. During egg incubation, she rarely comes at the surface for feeding or other activities (Nakasone and Murai 1998).

\subsection{Data collection}

Forty-two burrows of large-sized ( $>15 \mathrm{~mm}$ carapace width) A. perplexa crabs (25 male burrows and 17 female burrows) were randomly selected to measure the temperature from two different locations in their habitat: (1) inside the crabs' burrows and (2) inside the soil near their burrows. We installed two temperature sensors (DS18B20 digital temperature sensor), the first one was installed inside a crab burrow, and the second one was installed inside soil within $10 \mathrm{~cm}$ of the burrow perimeter. The installation depth of both sensors was at $5 \mathrm{~cm}$. Previously, temperature sensors were used by Akhter et al (2018), Yue et al (2019), and Keeratipattarakarn et al (2020) to measure the soil temperature. A weather station and a temperature sensor from Davis Company (https://www.weatherlink.com) were installed to measure the air temperature (see Kuhapong and Tina 2019 for more details). The air, soil and burrow temperatures were collected every $30 \mathrm{~min}$ for 24 hours (see Keeratipattarakarn et al 2020). The same experimental setup was used for all 42 crab burrows. Before installing a sensor inside a crab burrow, the crab was caught to measure its carapace width to ensure that it was larger than $15 \mathrm{~mm}$ carapace width. We did not select small-sized crabs as it was difficult to enter the sensor inside small-sized crab burrows. After measuring the crab's body size, it was released to the same place where it was caught.

Each day, only one crab burrow (either male or female) was selected and two sensors were used to measure burrow and soil temperatures. After collecting temperature data from one burrow, the sensor was removed carefully and used for another crab burrow. We made sure that the installation and removal of sensors did not damage the crab burrow. It was not possible to measure male and female burrow temperatures on the same day since we had a lack of sensors. The duration of the day-time was counted as the observations of 6:00 up to and including 17:30, and the duration of the night-time was counted as those of 18:00 up to and including 5:30.

\subsection{Statistical analysis}

Before analysing data, normality and homogeneity of variances of data were tested using Shapiro-Wilk's and Levene's tests, respectively. Two-way ANOVA tests were used to (1) test the effects of time ( 24 hours of a day), and location types (air, soil, male/female crab burrows) on the location temperatures and (2) to test the effects of time (day and night), and location types (air, soil, male/female crab burrows) on the location temperatures. Data were reported as mean \pm standard error (SE), and all tests were considered statistically significant at $P<0.05$.

\subsection{Ethical statement}

Animal care and handling procedures followed the guidelines of Thailand's Wild Animal Reservation and Protection Act, B.E. 2535 (1992). No animal was harmed or 
removed from their habitat, and no animal nest was destroyed. This study does not include any human subject.

\section{Results}

\subsection{The temperature of air, soil, and crab burrows}

The maximum, minimum, and mean temperature of the air, soil, and crab burrows are shown in Table 1. In a day, the crab burrow temperature range was narrower than the soil temperature range.

3.2. Variation in air, soil, and fiddler crab burrow (male/female) temperatures in 24 hours of a day
It was observed that air, soil, and male burrow temperatures were different at different time (hours) in a day (time: $F_{47,3585}=159.46, P<0.001$; location types: $F_{2,3585}=$ 741.56, $P<0.001$; time*location types: $F_{94,3585}=5.93, P<$ 0.001) (Figure 1a). Similarly, air, soil, and female burrow temperatures were also different at different hours in a day (time: $F_{47,2448}=86.76, P<0.001$; location types: $F_{2,2448}=$ 296.34, $P<0.001$; time* location types: $F_{94,2448}=4.12, P<$ 0.001 ) (Figure 1b). Burrow temperature was lower than soil temperature from 8:00 to 17:30, but other times, burrow temperature was higher than soil temperature (Figure 1a and b). Air temperature was lower than soil and burrow temperatures in most of the time of a day (Figure 1a and $1 \mathrm{~b}$ ).

Table 1 Air, soil, and crab burrow temperatures $\left({ }^{\circ} \mathrm{C}\right)$ at day and night.

\begin{tabular}{|c|c|c|c|c|}
\hline Day/night & Locations & Maximum temperature & Minimum temperature & Mean $\pm S E$ \\
\hline & Air & 34.20 & 23.30 & $28.53 \pm 0.07$ \\
\hline \multirow[t]{3}{*}{ Day } & Soil & 39.40 & 25.00 & $30.67 \pm 0.10$ \\
\hline & Crab burrows & 35.60 & 25.00 & $29.74 \pm 0.08$ \\
\hline & Air & 30.40 & 23.20 & $25.82 \pm 0.04$ \\
\hline \multirow[t]{2}{*}{ Night } & Soil & 33.30 & 24.40 & $27.32 \pm 0.05$ \\
\hline & Crab burrows & 33.20 & 25.60 & $28.39 \pm 0.05$ \\
\hline
\end{tabular}

(a)

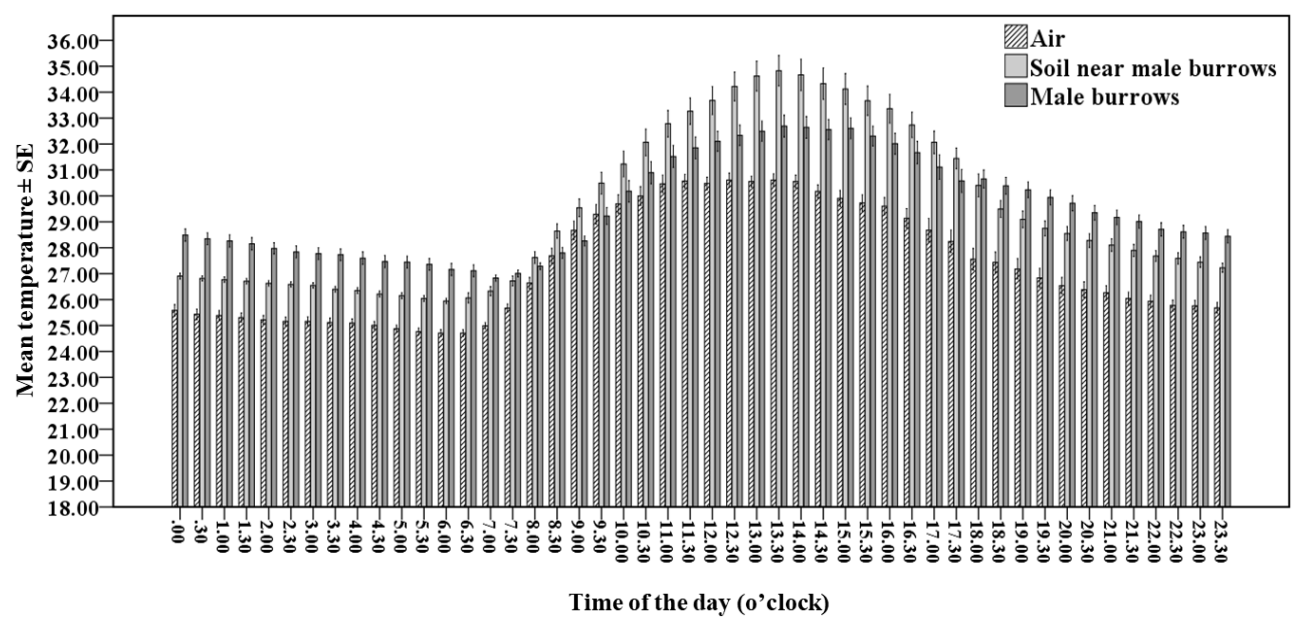

(b)

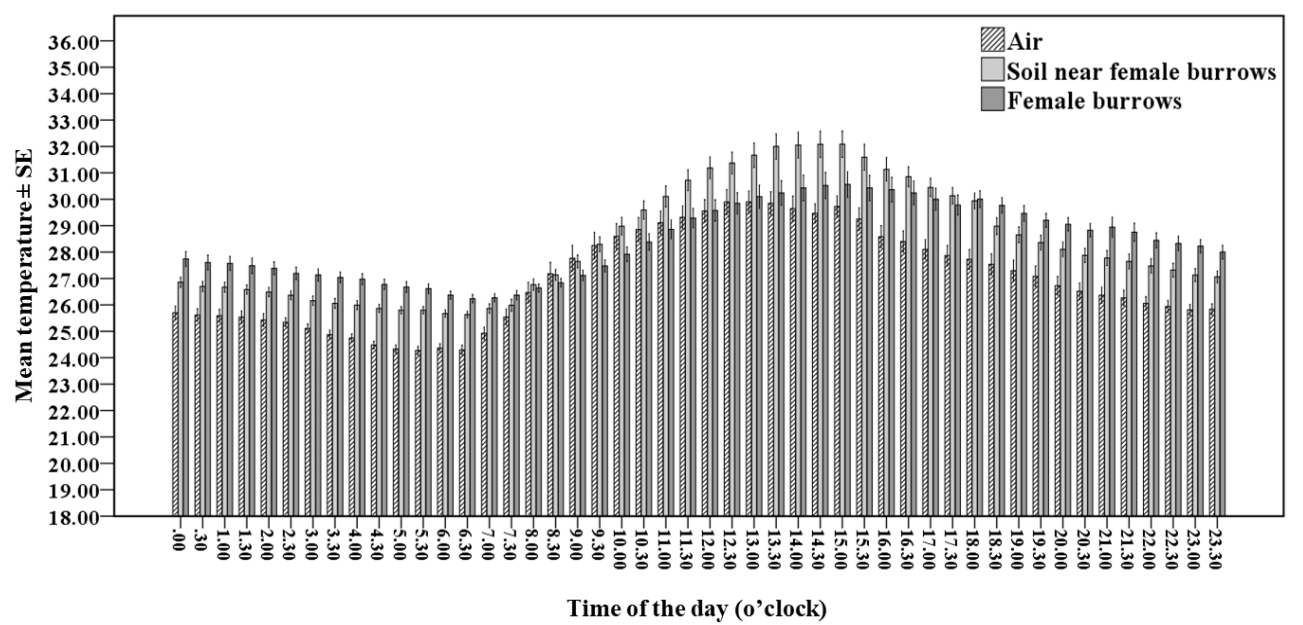

Figure 1 Location types and their temperatures $\left({ }^{\circ} \mathrm{C}\right.$ ) at 24 hours of a day; (a) air, soil, and male (Austruca perplexa) burrow temperatures, (b) air, soil, and female (A. perplexa) burrow temperatures. 
3.3. Variation in air, soil, and fiddler crab burrow (male/female) temperatures at day and night

Air, soil, and male burrow temperatures were different between day and night (day/night: $F_{1,3585}=1320.51$, $P<0.001$; location types: $F_{2,3585}=296.34, P<0.001$; day/night* location types: $F_{2,358}=62.37, P<0.001$ ) (Figure 2a). Male burrow temperatures were higher than air temperature $(P<0.001)$ but lower than soil temperature $(P<$ 0.001 ) during the day. On the other hand, at night, male burrow temperatures were higher than air $(P<0.001)$ and soil temperatures $(P<0.001)$ (Figure 2a).

Similarly, air, soil, and female burrow temperatures were different between day and night (day/night: $F_{1,2448}=$ 490.76, $P<0.001$; location types: $F_{2,2448}=132.43, P<0.001$; day/night* location types: $F_{2,2448}=46.13, P<0.001$ ) (Figure $2 b)$. Female burrow temperatures were higher than air temperature $(P<0.001)$ but lower than soil temperature $(P<$ 0.001) during the day. However, female burrow temperatures were higher than air $(P<0.001)$ and soil temperatures $(P<0.001)$ during the night (Figure $2 b)$.

(a)

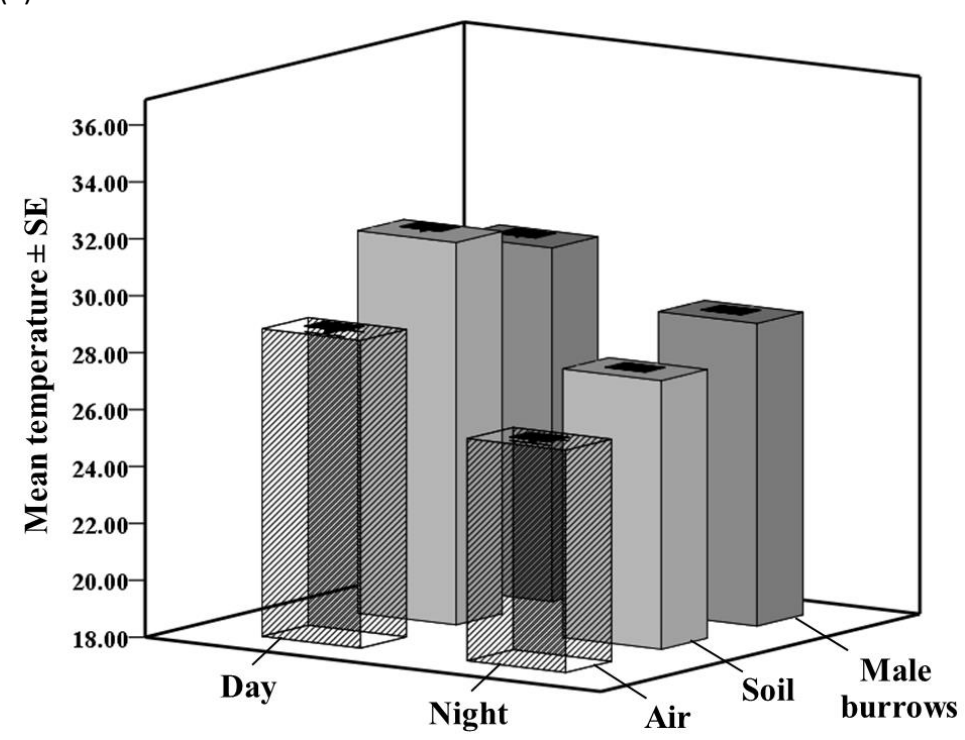

(b)

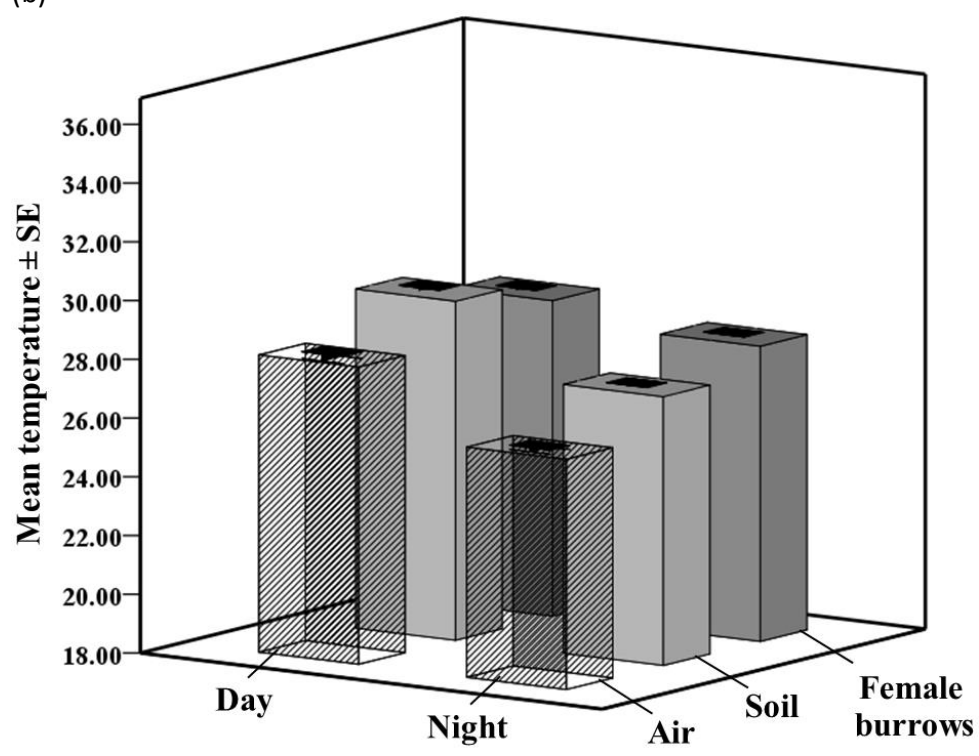

Figure 2 Location types and temperatures $\left({ }^{\circ} \mathrm{C}\right)$ at day and night; (a) air, soil, and male (Austruca perplexa) burrow temperatures; (b) air, soil, and female (A. perplexa) burrow temperatures.

\section{Discussion}

In this study, the crab burrow temperatures were lower during the day and higher at night than the soil temperature. It indicates that Austruca perplexa fiddler crabs use their burrows as a refuge during high temperatures in the day and low temperatures at night. In Nakhon Si Thammarat province, the climate is tropical, and soil temperature 
fluctuates frequently. The soil temperature range was 24-39 ${ }^{\circ} \mathrm{C}$. However, the burrow temperature range was $25-35^{\circ} \mathrm{C}$. It shows that the burrow temperature range was narrower compared to the soil temperature range. Moreover, though the maximum soil temperature was $39^{\circ} \mathrm{C}$, which was very high, burrow temperatures did not exceed $35{ }^{\circ} \mathrm{C}$. A few previous studies (Powers and Cole 1976; Wolfrath 1992; Keeratipattarakarn et al 2020) also showed that crab burrows maintained a suitable temperature during extreme temperatures.

Temperature fluctuation shows effects on the capacity of the crabs to live in an open and harsh habitat (Thurman 1998; Principe et al 2018). Extremely high temperature creates a potentially lethal problem to the fiddler crabs living in a tropical environment. For example, it affects the heart rate of the fiddler crabs; producing 100 beats/min from 20 to $25{ }^{\circ} \mathrm{C}, 140$ beats/min at $35{ }^{\circ} \mathrm{C}, 180$ beats/min at $40{ }^{\circ} \mathrm{C}$, and then heartrate steeply declines to near zero when the temperature becomes $50{ }^{\circ} \mathrm{C}$ (Levinton et al 2020). It indicates that the heartrates of fiddler crabs are temperature sensitive. Not only heartrates but also ventilator and cardiac performance of the crabs are affected by extreme temperature. Frederich and Pörtner (2000) observed that temperature higher than the optimal peak reduced the ventilator and cardiac performance of crabs. Furthermore, in fiddler crabs, a higher temperature reduces the hepatosomatic index, which means using energy reserves increases during high temperatures (da Silva Vianna et al 2020). For these reasons, crabs require maintaining a suitable body temperature and they can do it by using several mechanisms. Smith and Miller (1973) found that moving into the shade, keeping bodies wet, changing body colour, or orienting to the sun or wind are effective ways for the fiddler crabs to maintain a suitable body temperature. Eshkey et al (1995) observed that evaporation is an effective cooling method for fiddler crabs. However, constructing burrows and staying inside the burrows is another effective way to control body temperature (Smith and Miller 1973; Powers and Cole 1976; Wolfrath 1992; Eshkey et al 1995). Fiddler crabs burrows are effective enough to maintain a suitable temperature during day and night (Wolfrath 1992; Powers and Cole 1976; Keeratipattarakarn et al 2020). When fiddler crabs return to their burrows, their body temperature closely follows the burrow temperature, with a slight difference between the burrow temperature and the crab's body temperature (Edney 1961; Eshky et al 1995).

\section{Conclusions}

This study shows that burrows of fiddler crabs (Austruca perplexa) on a muddy sandy flat can keep temperature cooler during the day and warmer at night compared to the soil temperature in a tropical environment. This study also shows that the burrow temperature range was narrower than the soil temperature range. It indicates that fiddler crab burrows act as a refuge through maintaining a suitable temperature all day. When the temperature is very high or low, A. perplexa fiddler crabs may control their body temperature by frequently returning to their burrows and staying inside the burrows. Further study should investigate the temporal variations of air, soil, and fiddler crab burrow temperatures in other habitats (e.g., mangroves and salt marshes).

\section{Acknowledgments}

This study was supported by the Faculty of Science and Technology, Nakhon Si Thammarat Rajabhat University, Thailand. We are thankful to the villagers of Ban Nai Thung for taking care of the sensors when we were not in the field.

\section{Conflict of Interest}

The authors declare no conflict of interest.

\section{Funding}

Faculty of Science and Technology, Nakhon Si Thammarat Rajabhat University, Thailand.

\section{References}

Akhter T, Ali M, Cha J, Park SJ, Jang G, Yang KW, Kim HJ (2018). Development of a data acquisition system for the long-term monitoring of Plum (Japanese apricot) farm environment and soil. Journal of Biosystems Engineering 43:426-439.

Allen BJ, Rodgers B, Tuan Y, Levinton JS (2012). Size-dependent temperature and desiccation constraints on performance capacity: implications for sexual selection in a fiddler crab. Journal of Experimental Marine Biology and Ecology 438:93-99.

Bertness MD, Miller T (1984) Fiddler crab burrow dynamics across a New England salt marsh. Journal of Experimental Marine Biology and Ecology 83:211-237.

Bradley PM, Morris JT (1990) Influence of oxygen and sulfide concentration on nitrogen uptake kinetics in Spartina alterniflora. Ecology 71:282-287.

Chapman MG, Underwood AJ (1996) Influences of tidal conditions, temperature and desiccation on patterns of aggregation of the high-shore periwinkle, Littorina unifasciata, in New South Wales, Australia. Journal of Experimental Marine Biology and Ecology 196:213-237.

Chou CC, Head ML, Backwell PRY (2019) Effects of temperature on reproductive timing and hatching success in a tropical fiddler crab. Biological Journal of the Linnean Society 128:817-827.

Christy JH (1982) Burrow structure and use in the sand fiddler crab, Uca pugilator (Bosc). Animal Behaviour 30:687-694.

Christy JH (1987) Female choice and the breeding behavior of the fiddler crab Uca beebei. Journal of Crustacean Biology 7:624-635.

Christy JH, Salmon M (1984) Ecology and evolution of mating systems of fiddler crabs (genus Uca). Biological Reviews 59:483-509.

Colpo KD, López-Greco LS (2017) Temperature influences the reproduction of fiddler crabs at the southern edge of their distribution. Invertebrate Biology 136:171-183.

Crane J (1975) Fiddler crabs of the world. Ocypodidae: genus Uca. Princeton University Press, Princeton, NJ.

da Silva Vianna B, Miyai CA, Augusto A, Costa TM (2020) Effects of temperature increase on the physiology and behavior of fiddler crabs. Physiology and Behavior 215:112765.

Edney EB (1961) The water and heat relationships of fiddler crabs (Uca spp.). Transactions of the Royal Society of South Africa 36:71-91. 
Eshky AA, Atkinson RJA, Taylor AC (1995) Physiological ecology of crabs from Saudi Arabian mangrove. Marine Ecology Progress Series 126:83-95.

Frederich M, Pörtner HO (2000). Oxygen limitation of thermal tolerance defined by cardiac and ventilatory performance in spider crab, Maja squinado. American Journal of Physiology-Regulatory, Integrative and Comparative Physiology 279:R1531-R1538.

Howarth RW, Teal JM (1979) Sulfate reduction in a New England salt marsh. Limnology and Oceanography 24:999-1013.

Jones CG, Lawton JH, Shachak M (1994) Organisms as ecosystem engineers. Oikos 69:373-386.

Keeratipattarakarn K, Tina FW, Jaroensutasinee M, Jaroensutasinee K, Chumsri A, Chumsri I (2020) Burrow characteristics and temporal variation in burrow temperature of the fiddler crab Tubuca rosea (Tweedie, 1937) (Brachyura, Ocypodidae) in southern Thailand. Crustaceana 93:1153-1167.

Koch MS, Mendelssohn IA, McKee KL (1990) Mechanism for the hydrogen sulfide-induced growth limitation in wetland macrophytes. Limnology and Oceanography 35:399-408.

Kristensen E (2008) Mangrove crabs as ecosystem engineers; with emphasis on sediment processes. Journal of sea Research 59:30-43.

Kuhapong U, Tina FW (2019) Real Time Monitoring System for Detecting Humidity in Palm Farms. Rajabhat Chiang Mai Research Journal, Special Issue: $164-170$.

Levinton J, Lord S, Higeshide Y (2015) Are crabs stressed for water on a hot sand flat? Water loss and field water state of two species of intertidal fiddler crabs. Journal of Experimental Marine Biology and Ecology 469:57-62.

Levinton JS, Volkenborn N, Gurr S, Correal K, Villacres S, Seabra R, Lima FP (2020) Temperature-related heart rate in water and air and a comparison to other temperature-related measures of performance in the fiddler crab Leptuca pugilator (Bosc, 1802). Journal of Thermal Biology 88:102502.

Matsumasa M, Murai M (2005) Changes in blood glucose and lactate levels of male fiddler crabs: effects of aggression and claw waving. Animal Behaviour 69:569-577.

McCraith BJ, Gardner LR, Wethey DS, Moore WS (2003) The effect of fiddler crab burrowing on sediment mixing and radionuclide profiles along a topographic gradient in a southeastern salt marsh. Journal of Marine Research 61:359-390.

McKee KL (1993) Soil physicochemical patterns and mangrove species distribution: reciprocal effects? Journal of Ecology 81:477-487.

Miller LP, Harley CD, Denny MW (2009) The role of temperature and desiccation stress in limiting the local-scale distribution of the owl limpet, Lottia gigantea. Functional Ecology 23:756-767.

Nakasone Y, Murai M (1998) Mating behavior of Uca lactea perplexa (Decapoda: Ocypodidae). Journal of Crustacean Biology 18:70-7.

Powers LW, Cole JF (1976) Temperature variation in fiddler crab microhabitats. Journal of Experimental Marine Biology and Ecology 21:141157.

Principe SC, Augusto A, Costa TM (2018) Differential effects of water loss and temperature increase on the physiology of fiddler crabs from distinct habitats. Journal of Thermal Biology 73:14-23.

Reaney LT, Backwell PRY (2007) Temporal constraints and female preference for burrow width in the fiddler crab, Uca mjoebergi. Behavioral Ecology and Sociobiology 61:1515-1521.

Resgalla JrC, Brasil EDS, Salomão LC (2007) The effect of temperature and salinity on the physiological rates of the mussel Perna perna (Linnaeus, 1758). Brazilian Archives of Biology and Technology 50:543-556.

Ruscoe IM, Shelley CC, Williams GR (2004) The combined effects of temperature and salinity on growth and survival of juvenile mud crabs (Scylla serrata Forskål). Aquaculture, 238:239-247.

Schneider KR (2008) Heat stress in the intertidal: comparing survival and growth of an invasive and native mussel under a variety of thermal conditions. The Biological Bulletin 215:253-264.
Smith WK, Miller PC (1973) The thermal ecology of two south Florida fiddler crabs: Uca rapax Smith and U. pugilator Bosc. Physiological Zoology 46:186207.

Somero GN (2002) Thermal physiology and vertical zonation of intertidal animals: optima, limits and cost of living. Integrative and Comparative Biology 42:780-789.

Sylla M, Stein A, Van Mensvoort MEF, Van Breemen N (1996) Spatial variability of soil actual and potential acidity in the mangrove agroecosystem of West Africa. Soil Science Society of America Journal 60:219-229.

Thurman CL (1998) Evaporative water loss, corporal temperature and the distribution of sympatric fiddler crabs (Uca) from south Texas. Comparative Biochemistry and Physiology - Part A: Molecular \& Integrative Physiology 119:279-286.

Tina FW (2020) Effects of competition, female size, and their distance on the claw-waving rate of male fiddler crabs (Brachyura, Ocypodidae). Animal Biology 70:1-11.

Tina FW, Jaroensutasinee M, Jaroensutasinee K (2015a) Effects of population density on female and male burrow characteristics in the fiddler crab, Uca bengali Crane, 1975. Crustaceana 88:1283-99.

Tina FW, Jaroensutasinee M, Jaroensutasinee K (2016) Sex and size affecting time allocations for activities in Uca annulipes (H. Milne Edwards, 1837). Crustaceana 89:759-773.

Tina FW, Jaroensutasinee M, Jaroensutasinee K (2018) Claw regeneration, waving display and burrow characteristics of Austruca perplexa $(\mathrm{H}$. Milne Edwards, 1852) (Brachyura, Ocypodidae) from southern Thailand. Crustaceana 91:1247-1257.

Tina FW, Jaroensutasinee M, Sutthakiet O, Jaroensutasinee K (2015b) The fiddler crab, Uca bengali Crane, 1975: population biology and burrow characteristics on a riverbank in southern Thailand. Crustaceana 88:791-807.

Tina FW, Keeratipattarakarn K, Jaroensutasinee M, Jaroensutasinee K (2019) Time allocations for different activities in the fiddler crab Tubuca rosea (Tweedie, 1937) (Brachyura, Ocypodidae). Journal of Animal Behaviour and Biometeorology 7:60-65.

Tina FW, Muramatsu D (2020) Size-dependent mating preference of the male fiddler crab Austruca perplexa. Ethology 126:68-75.

Twilley RR, Chen R (1998) A water budget and hydrology model of a basin mangrove forest in Rookery Bay, Florida. Marine and Freshwater Research 49:309-323.

Vernberg FJ, Vernberg WB (1966) Studies on the physiological variation between tropical and temperate zone fiddler crabs of the genus Uca - VII. Metabolic-temperature acclimation responses in southern hemisphere crabs. Comparative Biochemistry and Physiology 19:489-524.

Weinstein RB (1998) Effects of temperature and water loss on terrestrial locomotor performance in land crabs: integrating laboratory and field studies. American Zoology 38:518-527.

Wiessner A, Kappelmeyer U, Kuschk P, Kastner M (2005) Sulphate reduction and the removal of carbon and ammonia in a laboratory-scale constructed wetland. Water research 39:4643-4650.

Wolfrath B (1992) Burrowing of the fiddler crab Uca tangeri in the Ria Formosa in Portugal and its influence on sediment structure. Marine Ecology Progress Series 85:237-243.

Yoder JA, Reinsel KA, Welch JM, Clifford DM, Rellinger EJ (2005) Herding limits water loss in the sand fiddler crab, Uca pugilator. Journal of Crustacean Biology 25:141-145.

Yue R, Shen R, He Q, Wang J, Chen X, Du W, Tan Q, Chen L, Qin Y, Pu H, Zhang L, Huang $C$ (2019) Soil temperature and humidity monitoring system design for farm land based on ZigBee communication technology. DEStech Transactions on Environment, Energy and Earth Sciences, (icepe). 